Proceedings of the XXIII Conference on Applied Crystallography, Krynica Zdrój, Poland, September 20-24, 2015

\title{
Effect of the Boron Addition on the Structure of the Ni-Mn-Co-In Alloys
}

\author{
K. Prusik ${ }^{a, *}$, E. Matyja ${ }^{a}$, M. Zubko ${ }^{a}$, M. Kubisztal ${ }^{a}$ And A. ChrobaK ${ }^{b}$ \\ ${ }^{a}$ University of Silesia, Institute of Material Science, Bankowa 12, 40-007 Katowice, Poland \\ ${ }^{b}$ University of Silesia, Institute of Physics, Uniwersytecka 4, 40-007 Katowice, Poland
}

\begin{abstract}
Series of $\mathrm{Ni}_{45.5-x} \mathrm{Co}_{4.5} \mathrm{Mn}_{36.6} \mathrm{In}_{13.4} \mathrm{~B}_{x}$ (at.\%, $x=0,0.05,0.1,0.5,1.0$ ) polycrystalline magnetic shape memory alloys produced by the induction melting were examined in terms of the structure and transition temperatures. The structure of the alloys was determined by the X-ray diffraction and transmission electron microscopy. Scanning electron microscopy and electron backscattering diffraction techniques were applied to obtain the microstructure and texture of alloys. Boron addition promotes nucleation of the second Co-rich and In-poor phase as well as causes decrease of the martensitic transformation temperatures.

DOI: 10.12693/APhysPolA.130.1023

PACS/topics: 71.20.Lp, 71.20.Be
\end{abstract}

\section{Introduction}

Magnetic shape memory alloys exhibit reversible martensitic transformation which may be driven by temperature, external strain or magnetic field resulting in macroscopic shape change. Large recoverable strain and high frequency response make these materials promising magnetic actuators [1]. Magnetic-field induced strain about $10 \%$ was observed for $\mathrm{Ni}-\mathrm{Mn}-\mathrm{Ga}$ single crystals, for which shape memory effect is realized by martensitic variant reorientation [2]. Until now several alloy systems have been developed as MSMA, e.g. Ni-Mn$\mathrm{Ga}$ [1], $\mathrm{Co}-\mathrm{Ni}-\mathrm{Ga}[3,4], \mathrm{Fe}-\mathrm{Pt}, \mathrm{Co}-\mathrm{Ni}-\mathrm{Al}, \mathrm{Fe}-\mathrm{Pd}$ and $\mathrm{Ni}-\mathrm{Fe}-\mathrm{Ga}$ [5]. New candidates for magnetic shape memory alloys e.g. $\mathrm{Ni}-\mathrm{Mn}-\mathrm{X}(\mathrm{In}, \mathrm{Sn}, \mathrm{Sb})$ have attracted much attention, because for these alloys shape recovery can be obtained by the magnetic field-induced reverse transformation which is called "metamagnetic transformation". So in this new type of metamagnetic shape memory alloys (MMSMA) martensitic transformation temperature (to the ferromagnetic parent phase) can be controlled by a magnetic field. Additionally, large magnetic-field induced-stress over $100 \mathrm{MPa}$ was observed in $\mathrm{Ni}_{45} \mathrm{Co}_{5} \mathrm{Mn}_{36.7} \mathrm{In}_{13.3}$ single crystal [6]. Co in this alloy is added to increase the Curie temperature. The magnetic shape memory effect can be improved in polycrystalline alloys produced by directional solidification, processed by high temperature plastic deformation methods [7], extrusion [8], etc. Additionally, $\mathrm{Ni}-\mathrm{Mn}-$ In alloy which exhibits a large magnetocaloric effect can be used in environmentally friendly magnetic refrigerators [9]. However, these alloys are very brittle. It is known that the grain size refinement results in an improvement of the mechanical properties. Significant grain refinement was achieved through addition a small amount of boron to e.g. Ti-alloys [10], Ni-Mn-Ga [11], furthermore improvement in mechanical properties was achieved e.g. in steel [12].

\footnotetext{
*corresponding author; e-mail: krystian.prusik@us.edu.pl
}

In this paper the effect of the boron addition on the structure of $\mathrm{Ni}_{45.5} \mathrm{Co}_{4.5} \mathrm{Mn}_{36.6} \mathrm{In}_{13.4}$ (at.\%) alloy was studied.

\section{Experimental procedure}

Polycrystalline $\mathrm{Ni}_{45.5-x} \mathrm{Co}_{4.5} \mathrm{Mn}_{36.6} \mathrm{In}_{13.4} \mathrm{~B}_{x}$ (at.\%, $x=0$ (B000), 0.05 (B005), 0.1 (B010), 0.5 (B050), 1.0 (B100)) alloys were produced by the induction melting under argon atmosphere. Ingots were homogenized at $1173 \mathrm{~K}$ for $24 \mathrm{~h}$ in vacuum and quenched into icy water. The structure was examined by X-ray diffraction (XRD) (Philips model $\mathrm{X}^{\top}$ Pert). The phase transformation temperatures were determined by differential scanning calorimeters (DSC, Mettler Toledo) with cooling/heating rate of $10 \mathrm{~K} / \mathrm{min}$. The microstructure was observed by the scanning electron microscope (SEM, JEOL JSM6480) after electropolishing in $\mathrm{HNO}_{3}$ + ethanol with current $0.5 \mathrm{~A}$ and voltage $15-20 \mathrm{~V}$. Transmission electron microscopy (TEM) was carried out by JEOL JEM3010. Texture was examined by electron backscatter diffraction (EBSD) technique by using HKL system and NordlysII camera.

\section{Results and discussion}

As it is shown in the SEM images, depending on amount of the boron addition different microstructures of B000-B100 alloys were observed (Fig. 1a-e). For all alloys the coarse grain microstructure of matrix was observed. Grains size varies from $200 \mu \mathrm{m}$ to even $\mathrm{mm}$. Additionally, for the alloys B010, B050, and B100 the second phase precipitates were seen (Fig. 1c-e). It was expected that addition of the boron, like in the other alloys systems (e.g. Ti-alloys [10]), will cause the grains refinement. But this effect was not observed. Instead of that, due to the applied annealing, the precipitation process occurred.

It appears that boron addition promotes nucleation of the second phase. As one can see in Fig. 1c-f volume fraction of precipitates increases with the boron addition. In case of B100 alloy the amount of the second phase is the highest observed so the precipitates are located inside 

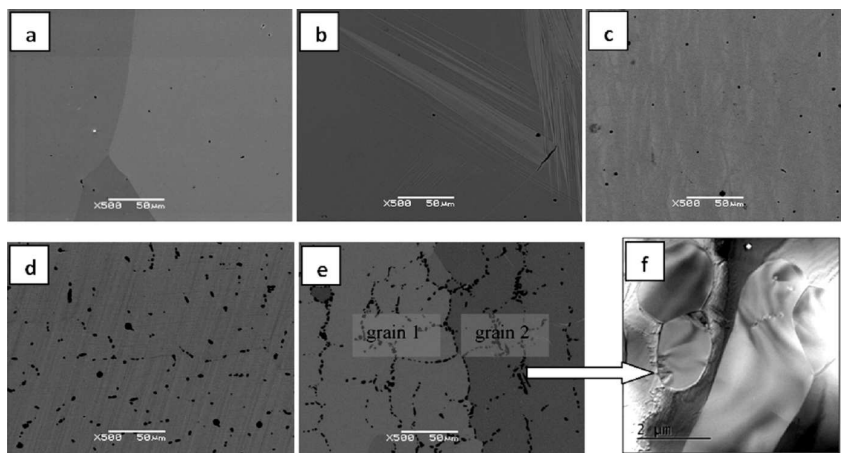

Fig. 1. SEM microstructure of B000 (a), B005 (b), B010 (c), B050 (d), B100 (e) alloy. TEM bright field (TEM BF) image of B100 alloy (f).

the matrix grains as well as decorate grain boundaries creating kind of "subgrains" in the matrix. Structure of the precipitates were studied by TEM (Fig. 1f). The average size of the second phase grains is about $1-2 \mu \mathrm{m}$. Additionally, for the B005 alloys the martensitic plates were observed (Fig. 1b). Chemical analyses done by EDS revealed that precipitates are richer in Co and poorer in Ni than the matrix (Fig. 2). The concentration of elements in the precipitates does not change much with the boron addition. In the B050 and B100 specimens precipitates consist of about 38 at. $\%$ of $\mathrm{Ni}, 33$ at. $\%$ of Mn, 27 at.\% of Co and 2 at.\% of In. Due to the EDS method limitations the boron concentrations were not determined. To do deeper analysis, in the future work it would be worthwhile to measure the boron distribution which may be done e.g. by electron energy loss spectroscopy (EELS). To determine structure of the phases XRD, TEM, and EBSD were used. Figure 3 shows the XRD patterns of $\mathrm{Ni}_{45.5-x} \mathrm{Co}_{4.5} \mathrm{Mn}_{36.6} \mathrm{In}_{13.4} \mathrm{~B}_{x}$ (at.\%) alloys. For all specimen high-temperature $L 2_{1}$ phase with cubic lattice $a_{0}=5.98 \AA$ was identified at ambient temperature.

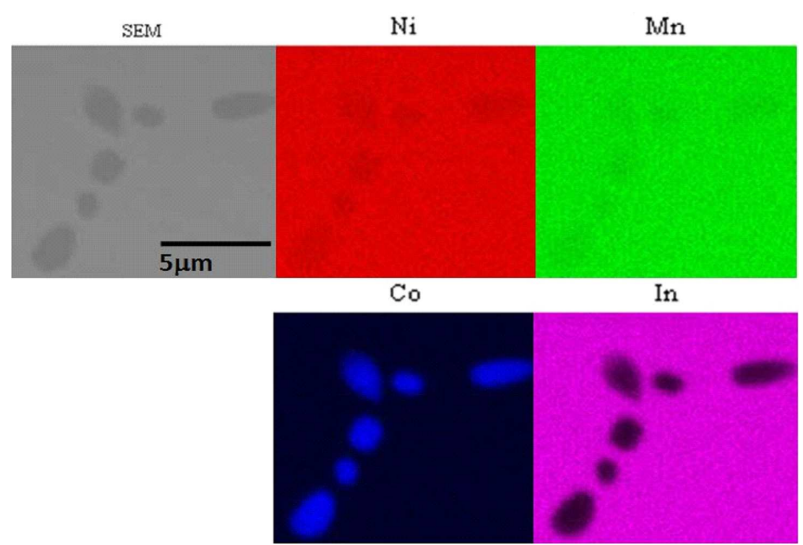

Fig. 2. EDS elemental maps of B100 alloy.

Due to the coarseness of the grain not all peaks corresponding to the $L 2_{1}$ pattern with lattice parameter $5.98 \AA$ were present. The precipitates were identified

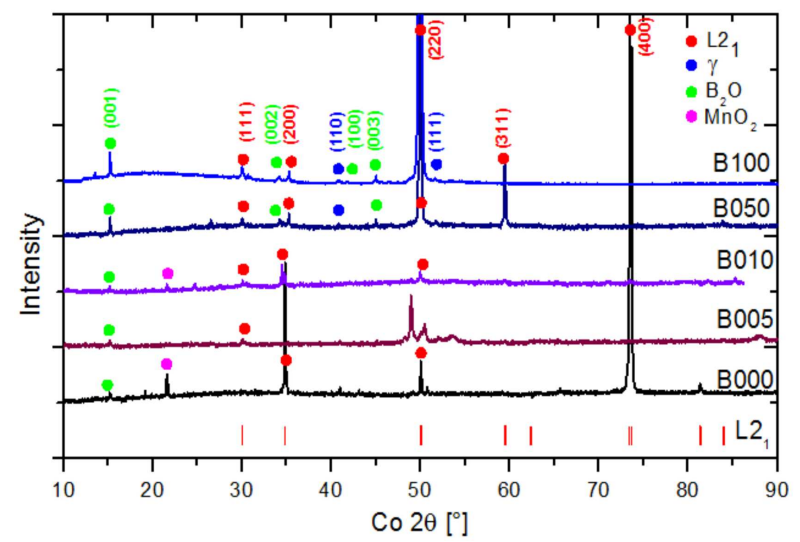

Fig. 3. XRD patterns of B000-B100.

as a mixture of $A 1$ type cubic $\gamma$ structure with cubic lattice $a_{0}=3.59 \AA$ (Fig. 3 ) and $\mathrm{M}_{23} \mathrm{~B}_{6}$. The small volume of oxides $\mathrm{B}_{2} \mathrm{O}$ and $\mathrm{MgO}_{2}$ were found. In the $\mathrm{B} 100$ alloy the broad peak between $0-30^{\circ} 2 \theta$ was also noticed. It can be connected with the amorphization process but it needs further studies. In the B005 specimen the martensite plates were observed. The structure of the martensite was confirmed by TEM and EBSD measurements (Fig. 4) as seven-layered monoclinic martensite $7 \mathrm{M}$ (denoted also as $14 \mathrm{M})$ with lattice parameter $a_{0}=4.23 \AA, b_{0}=5.62 \AA$, $c_{0}=21 \AA, \alpha=90^{\circ}, \beta=89.9^{\circ}$.
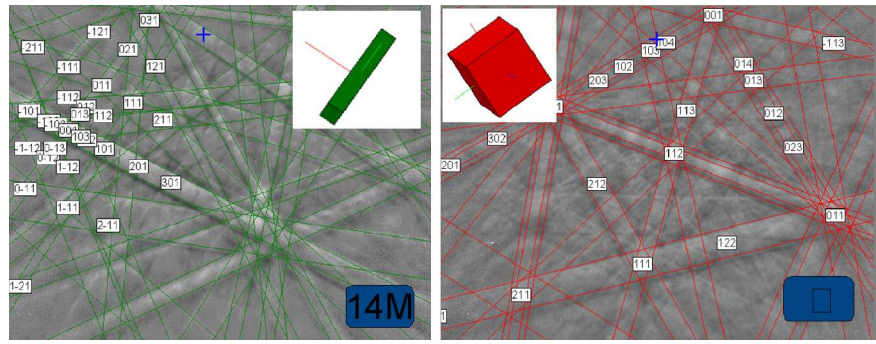

Fig. 4. Experimental EBSD Kikuchi pattern overlaying with the fitted one of the $14 \mathrm{M}$ martensite and $\gamma$ precipitate.

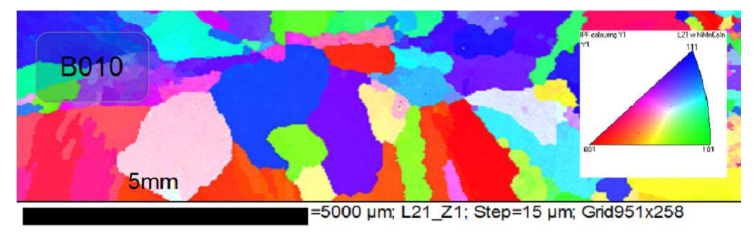

Fig. 5. EBSD OIM of the B010 specimen.

Crystallographic orientations of the parent $L 2_{1}$ phase were measured by EBSD technique. The example of orientation image map (OIM) for parent phase of B010 specimen was shown in Fig. 5. The color indicates the crystal orientation perpendicular to the ingots axis. As one can see the coarse grains are statistically oriented inside the specimen.

In the B050 and B100 specimens, precipitates are also randomly oriented in the matrix. No texture and any spe- 
cific crystallographic orientation relationships between the matrix and the precipitates were confirmed. Martensitic transformation behavior was studied by differential scanning calorimetry (DSC).

The endothermal and exothermal peaks were observed for B000, B005, and B010 alloys unlike B050 and B100 for which the martensite transformation was not observed. The results of the DSC measurements were depicted in Table I. The DSC curves for B010 specimen was shown in Fig. 6. The clear trend in shifting transformation temperatures $\left(M_{s}\right.$ - martensitic start, $M_{f}$ - martensitic finish, $A_{s}$ - austenite start, $A_{f}$ - austenite finish) with boron addition were not confirmed. On the one hand, the major factor which is connected with the transformation temperatures is valence electron concentration $e / a$. When the content of boron is above the certain value (in this work $0.5-1.0$ at.\% B) the transformation is hindered. This is because during the precipitation process significant part of cobalt dissolved in the matrix diffuses to the precipitates.

Characteristic transformation

TABLE I temperatures in $\left[{ }^{\circ} \mathrm{C}\right]$ of B000-B010 alloys.

\begin{tabular}{c|c|c|c|c}
\hline \hline Sample & $M_{s}$ & $M_{f}$ & $A_{s}$ & $A_{f}$ \\
\hline B000 & -7 & -15 & 9 & 19 \\
B005 & 48 & 2 & 24 & 62 \\
B010 & -9 & -16 & 2 & 9
\end{tabular}

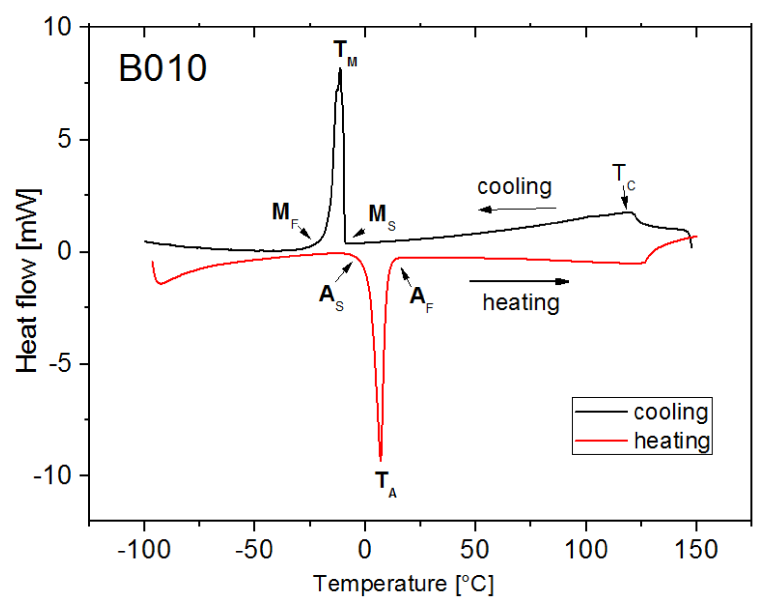

Fig. 6. DSC curves of the B010 specimen.

So that the $e / a$ of the matrix is lower and as a result the martensitic transformation temperatures decreases. On the other hand, for the B005 alloy the increase of the transformations temperatures with the boron addition was observed. To be sure about the homogeneity and treatment of the sample we produced the second ingot of exactly the same chemical composition and thermally treated as previous. The observed microstructure, transformation temperatures etc. were the same.

The abnormal behavior of that alloy is under study now. The abrupt change in the DSC curves around $120^{\circ} \mathrm{C}$ is connected with magnetic transformation $T_{\mathrm{C}}^{\mathrm{A}}$ (the Curie temperature of austenite) (Fig. 6).

\section{Summary}

The effect of the boron addition on the structure, texture, and martensitic transformation of the alloy Ni45:5$x$ Co4:5Mn36:6In13:4B $x$ (at. $\%, x=0,0.05,0.1,0.5,1$ ) were examined. For all alloys the coarse grain microstructure of matrix was observed. At room temperature the matrix was identified as cubic lattice $L 2_{1}$ (B2) with lattice parameter $5.98 \AA$. Additionally, in alloy containing $0.05 \%$ of $\mathrm{B}$ the seven-layered martensite $7 \mathrm{M}$ (monoclinic) with lattice parameter $a_{0}=4.23 \AA, b_{0}=5.62 \AA$, $c_{0}=21 \AA, \alpha=90^{\circ}, \beta=89.9^{\circ}$ was identified. Boron addition of $0.1-1$ at.\% causes precipitation of $\mathrm{Co}-$ rich and In-poor $\gamma$ and $\mathrm{M}_{23} \mathrm{~B}_{6}$ phases. The boron addition promotes nucleation of the second phase. Volume fraction of precipitates increases with the boron addition. Particles are located inside the matrix grains as well as decorates grain boundaries, creating (for alloy consisting 1.0 at.\% of B) kind of "subgrains". During the precipitation cobalt dissolved in the matrix diffuses to the precipitates lowering the $e / a$ ratio and the martensitic transformation temperatures as well. Precipitates are randomly oriented in the matrix. No texture and any specific crystallographic orientation relationships between the matrix and the precipitates were confirmed.

\section{Acknowledgments}

Research was financially supported by the Polish Ministry of Science and Higher Education under the project no. N507 518639.

\section{References}

[1] K. Ulakko, Mater. J. Mater. Eng. Perform. 5, 405 (1996).

[2] A. Sozinov, A.A. Likhachev, N. Lanska, K. Ullakko, Appl. Phys. Lett. 80, 1746 (2002).

[3] K. Prusik, B. Kostrubiec, T. Goryczka, G. Dercz, P. Ochin, H. Morawiec, Mater. Sci. Eng. A 481482, 330 (2008).

[4] K. Prusik, H. Morawiec, B. Kostrubiec, M. Prewendowski, G. Dercz, K. Ziewiec, Eur. Phys. J. Spec. Topics 158, 155 (2008).

[5] M.L. Corróa, S. Kustov, E. Cesari, Y.I. Chumlyakov, Mater. Sci. Eng. A 521-522, 201 (2009).

[6] R. Kainuma, Y. Imano, W. Ito, Y. Sutou, Nature 439, 957 (2006).

[7] H. Morawiec, T. Goryczka, A. Drdzeń, J. Lelątko, K. Prusik, Solid State Phenom. 154, 133 (2009).

[8] K. Prusik, K. Bałdys, D. Stróż, T. Goryczka, J. Lelątko, Solid State Phenom. 203-204, 306 (2013).

[9] Z.D. Han, D.H. Wang, C.L. Zhang, S.L. Tang, B.X. Gu, Y.W. Du, Appl. Phys. Lett. 89, 182507 (2006).

[10] S. Tamirisakandala, R.B. Bhat, J.S. Tiley, D.B. Miracle, Scr. Mater. 53, 1421 (2005).

[11] M. Ramudu, A. Satish Kumar, V. Seshubai, Intermetallics 28, 51 (2012).

[12] S.N. Ghali, H.S. El-Faramawy, M.M. Eissa, J. Miner. Mater. Character. Eng. 11, 995 (2012). 